\title{
Inheritance of Carotenoid Content in Tetraploid $x$ Diploid Potato Crosses
}

\author{
Kathleen G. Haynes ${ }^{1}$ \\ U.S. Department of Agriculture (USDA), Agricultural Research Service (ARS), Plant Sciences \\ Institute, Genetic Improvement of Fruits and Vegetables Laboratory, 10300 Baltimore Avenue, \\ Building 010A, Beltsville, MD 20705 \\ Beverly A. Clevidence and David Rao \\ USDA-ARS, Beltsville Human Nutrition Research Center, Food Components and Health Laboratory, \\ Beltsville, MD 20705 \\ Bryan T. Vinyard \\ USDA-ARS, Biometrical Consulting Service, Beltsville, MD 20705
}

\begin{abstract}
Additional INDEX words. Solanum tuberosum, Solanum phureja, Solanum stenotomum, yellow-flesh, zeaxanthin, antheraxanthin, violaxanthin, neoxanthin, lutein

Abstract. Carotenoids have a wide range of human health benefits. Yellow-fleshed tetraploid potato (Solanum tuberosum) cultivars have more than twice the concentration of carotenoids as white-fleshed cultivars. However, carotenoid concentrations in some diploid potatoes have been reported to be up to 13 times higher than in 'Yukon Gold', the most popular yellow-fleshed potato cultivar grown in the United States, and up to 22 times higher than in white-fleshed potatoes. The purpose of this study was to determine the feasibility of using these high-carotenoid diploids to develop high-carotenoid tetraploid germplasm. Three diploid clones with high (dark yellow-flesh), moderate (moderate yellowflesh), and low (white-cream-flesh) carotenoid levels that produced $2 \mathrm{n}$ pollen were crossed with a light yellow-fleshed tetraploid advanced breeding selection to determine the inheritance of carotenoid content. Twenty-six to 43 progeny from these three $4 x-2 x$ families were grown in a replicated field experiment in Presque Isle, ME, for 2 years. After harvest, carotenoids were extracted and quantified by high-performance liquid chromatography in 13 to 14 randomly selected clones from each family; however, flesh color was scored as white or yellow in all progeny. A continuous distribution of carotenoid concentration with high- and low-carotenoid segregants was observed in all three families. There were no significant differences among these three families for individual or total carotenoid concentrations; however, there were significant differences among clones within families. Broad-sense heritability estimates were high for total carotenoid $(0.81)$, lutein $(0.77)$, zeaxanthin $(0.73)$, and the lycopene beta-cyclase pathway carotenoids $(0.73)$; moderate for neoxanthin (0.42); and low for violaxanthin (0.21) and antheraxanthin (0.13). Based on flesh color segregation, the two yellow-fleshed diploid parents were heterozygous for the Chy 2 allele governing yellow-flesh and produced $2 \mathrm{n}$ gametes by a second division restitution mechanism. It appears that selection for high-carotenoid tetraploid germplasm can be made from within any family with at least one yellow-fleshed parent. Selections will have to be made on an individual clonal basis rather than on a family basis.
\end{abstract}

Consumers have embraced the concept of buying colorful vegetables for their antioxidant activity and for their eye appeal. These and other quality factors have given yellow-fleshed potatoes such as 'Yukon Gold' an edge in the fresh potato market and have motivated plant geneticists to develop yellow-fleshed cultivars with more intense yellow coloring. The pigments in these potatoes are xanthophylls and include the carotenoids lutein and zeaxanthin. These carotenoids are of keen interest in the nutritional sciences where they are under study for protection against an array of chronic diseases, including cataract, macular degeneration, heart disease, and cancer (Mares-Perlman et al., 2002) and for preserving mental acuity (Johnson et al., 2008; Morris et al., 2006).

White-fleshed potatoes are low in carotenoids [less than 100 $\mu \mathrm{g} / 100 \mathrm{~g}$ fresh weight $(\mathrm{FW})]$, whereas the carotenoid content of yellow-fleshed potato cultivars of the Tuberosum group may be two to five times higher (Lu et al., 2001; Nesterenko and Sink,

Received for publication 19 Apr. 2011. Accepted for publication 2 June 2011. We thank Mary Camp for preparing the zeaxanthin and lutein figures.

${ }^{1}$ Corresponding author. E-mail: kathleen.haynes@ars.usda.gov.
2003; Tevini and Schonecker, 1986). Despite dietary recommendations, the richest sources of lutein and zeaxanthin, darkgreen leafy vegetables such as kale (Brassica oleracea) and spinach (Spinacia oleracea), are poorly consumed in the United States. Thus, enriching these carotenoids in potatoes and other commonly consumed foods could be an effective strategy for preventing or delaying a number of age-related diseases, particularly macular degeneration and declining mental acuity, that limit quality of life.

The yellow-fleshed trait in potatoes has long been known to be the result of a dominant allele at the $Y$ locus (Fruwirth, 1912). Recent research has shown that the yellow-fleshed trait is the result of a dominant allele of beta-carotene hydroxylase, designated Chy 2 allele 3 by Wolters et al. (2010) or Bch by Brown et al. (2006). Wolters et al. (2010) have reported that the other 10 alleles of Chy2 have no influence on the yellow-flesh trait.

Genetic variation for carotenoid content exists in potatoes, and the amount of genetic variation as a proportion of the phenotypic variation is quite large (Haynes et al., 2010; Reddivari et al., 2007). Concentrations of carotenoids greater than $1400 \mu \mathrm{g} / 100 \mathrm{~g}$ 
FW have been reported in diploid hybrid clones of Solanum phureja-Solanum stenotomum (Lu et al., 2001) and greater than $2000 \mu \mathrm{g} / 100 \mathrm{~g}$ FW have been reported in other Solanum species germplasm (Andre et al., 2007; Brown et al., 2006). Genotype $\times$ environment interactions are also significant for carotenoid content in potato (Haynes et al., 2010; Reddivari et al., 2007), although much smaller in magnitude than genetic variation. What specific environmental factors may be contributing to these interactions is currently unknown in potatoes.

Commercial potatoes are tetraploid, whereas the highcarotenoid clones identified to date have been diploid (Brown et al., 1993; Lu et al., 2001). Ploidy levels can be manipulated through the use of $2 n$ gametes; diploids producing $2 n$ gametes can be crossed directly with tetraploids to produce tetraploid offspring (Mok and Peloquin, 1975). This allows for the rapid transfer of valuable traits from the diploid level to the tetraploid level. As of this time, no method exists for estimating narrowsense heritability, which is the ratio of additive genetic variance to phenotypic variance, in $4 x-2 x$ crosses because the genetic covariance between a diploid parent and its tetraploid offspring is composed of three covariance components (Haynes, 1990). However, broad-sense heritability, defined as the proportion of genetic variance to phenotypic variance, can be estimated (Nyquist, 1991).

The objective of this research was to determine the feasibility of using high-carotenoid diploids to develop high-carotenoid tetraploid germplasm to enhance the breeding of nutritionally improved cultivars.

\section{Materials and Methods}

Plant materials. Controlled pollinations were made between a light yellow-fleshed tetraploid potato clone from the U.S. Department of Agriculture-Agricultural Research Service (USDA-ARS) Beltsville Potato Breeding Program (B1425-9) and three $2 \mathrm{n}$ pollen-producing diploid potato clones from a hybrid population of $S$. phureja-S. stenotomum (phu-stn) (BD296-2, BD317-4, BD322-1) to produce three 4x-2x families. The three families were designated BTD0218 (B1425-9 $\times$ BD296-2), BTD0220 (B1425-9 × BD317-4), and BTD0223 (B1425-9 $\times$ BD322-1), where B indicates a tetraploid clone from the USDA-ARS Beltsville Potato Breeding Program, BTD indicates a Beltsville tetraploid $\times$ diploid clone, and BD indicates a Beltsville diploid clone. The tetraploid parent, B1425-9, was a selection from a cross of 'Atlantic' (a white-fleshed chipping cultivar) and BTD0001-8 [a 4x-2x hybrid between a whitefleshed tetraploid selection (B0749-2FF) with frost resistance and a yellow-fleshed diploid clone (DM91-5) from the North Carolina phu-stn population (Haynes et al., 1989)]. Total carotenoid contents in two of the diploid parental clones, BD296-2 and BD317-4, were reported to be 1435 and 682 $\mu \mathrm{g} / 100 \mathrm{~g} \mathrm{FW}$, respectively, which were $\approx 13$ and six times greater than the carotenoid content of 'Yukon Gold' (Lu et al., 2001). In both of these diploids, the proportion of zeaxanthin was $3.1 \%$ or less of the total carotenoid content ( $\mathrm{Lu}$ et al., 2001). The third diploid parent was a white-light cream-fleshed diploid, BD332-1. Lu et al. (2001) reported that there was an exponential relationship between yellow intensity and carotenoid content, so, although carotenoid content in this parent was not determined, it was expected to be low and less than 'Yukon Gold'. Thus, the carotenoid concentrations in BD296-2, BD317-4, and BD322-1 were high, intermediate, and low, re- spectively. The tetraploid parent had been discarded from the breeding program before the initiation of this study, and so we were not able to determine its carotenoid content. Because the extraction of carotenoids is a time-consuming process, carotenoid profiles of 13 to 14 randomly selected progeny from these three families were determined for this study. 'Yukon Gold' was included as a standard cultivar. However, all of the $4 x-2 x$ progeny generated were scored visually as being either yellow-fleshed or white-fleshed by cutting open their tubers. In all, there were 36, 26 , and 45 progeny generated for these three families, BTD0218, BTD0220, and BTD0223, respectively.

Field experiments. The $4 \mathrm{x}-2 \mathrm{x}$ clones and 'Yukon Gold' were planted 4 June 2008 and 3 June 2009 on a Caribou gravelly loam soil (fine-loamy, mixed, Frigid Typic Haplorthod) on Chapman Farm in Presque Isle, ME. The experimental design was a randomized complete block with two replications. Each plot consisted of six plants of one clone. Plants were spaced $23 \mathrm{~cm}$ within the row with $91 \mathrm{~cm}$ between rows and $69 \mathrm{~cm}$ between plots in the row. Plots were planted after a plowed down timothy-clover (Phleum pretens-Trifolium spp.) sod on site. The test location was fertilized with $168 \mathrm{~kg} \cdot \mathrm{ha}^{-1}$ nitrogen, 73.3 $\mathrm{kg} \cdot \mathrm{ha}^{-1}$ phosphorus, and $139.5 \mathrm{~kg} \cdot \mathrm{ha}^{-1}$ potassium banded in row at planting. No irrigation was available. Cultural practices were similar to those used on commercial farms in the area. At harvest, two tubers from each plot were cut and scored for flesh color in the field. Tubers from 13 to 14 randomly selected clones per family were harvested into paper bags from each plot on 11 Sept. 2008 and 26 Aug. 2009. Four medium-sized tubers, free of external defects or blemishes, were selected and shipped to Beltsville, MD, where they were held at $4{ }^{\circ} \mathrm{C}$ with $95 \%$ relative humidity storage until carotenoids were extracted. Tubers harvested in 2008 were evaluated for carotenoid content from 6 Oct. 2008 to 26 Jan. 2009; tubers harvested in 2009 were evaluated from 13 Oct. 2009 to 28 Jan. 2010.

Carotenoid extraction and identification. Carotenoid extraction and identification followed the procedures as reported in Haynes et al. (2010).

STATistical ANALYSES. Variables analyzed were zeaxanthin, antheraxanthin, violaxanthin, neoxanthin, total lycopene betacyclase (LCY-b) pathway carotenoids (zeaxanthin + antheraxanthin + violaxanthin + neoxanthin), lutein, and total carotenoid. Using SAS (Version 9.2; SAS Institute, Cary, NC) PROC GLIMMIX to obtain variance component estimates, two models were specified to examine variability: 1) among individual clones and 2) among families and siblings within family. Effects containing clone or family or sib(family) were modeled as random effects. Year was modeled as a fixed effect. These variance components estimates were used to obtain estimates of broad-sense heritability (Nyquist, 1991). Estimate statements were written to obtain best linear unbiased predictors for clone, year, clone $\times$ year, and family, year $\times$ family, year $\times \operatorname{sib}$ (family), and grand means. F-tests for all effects involving only year, clone, family, or sib(family) were obtained by specifying clone, family, and sib(family) to be fixed, rather than random, effects in the PROC GLIMMIX model specifications.

DETERMINING THE GENETIC COMPOSITION OF PARENTAL CLONES AT THE $\boldsymbol{C H Y}_{2}$ LOCus. Because only Chy 2 allele 3 is responsible for the dominant yellow-fleshed trait (Wolters et al., 2010), the white-fleshed diploid parent of the family BTD0223 was homozygous-recessive, designated chy 2 chy2. From this starting point, the genetic composition of the yellow-fleshed tetraploid parent and then the two diploid yellow-fleshed parents were 
determined by examining the segregation ratios of yellow:white flesh of the progeny from these three families. If a heterozygous diploid produced $2 \mathrm{n}$ gametes by a first division restitution mechanism, the frequency of $2 \mathrm{n}$ gametes Chy2Chy2, Chy 2 chy2, and chy 2 chy 2 would be $\beta / 4,1-(\beta / 2)$, and $\beta / 4$, respectively, whereas, if $2 n$ gametes were produced by a second division restitution mechanism, the frequencies would be (1- $\beta / 2), \beta$, and $(1-\beta / 2)$, respectively (Mendiburu and Peloquin, 1979), where $\beta$ is the frequency of single exchange tetrads and $0 \leq \beta \leq 1$.

\section{Results and Discussion}

There were significant differences between years for antheraxanthin, violaxanthin, and neoxanthin. Antheraxanthin was greater in 2008 than 2009 (127 versus $16 \mu \mathrm{g} / 100 \mathrm{~g} \mathrm{FW})$ as was violaxanthin (96 versus $32 \mu \mathrm{g} / 100 \mathrm{~g} \mathrm{FW}$ ). Neoxanthin was less in 2008 than 2009 (15 versus $80 \mu \mathrm{g} / 100 \mathrm{~g} \mathrm{FW})$. There were no significant differences between years for zeaxanthin, total LCY-b pathway carotenoids, lutein, and total carotenoids. Mean zeaxanthin, LCY-b pathway carotenoids, lutein, and total carotenoids averaged 122, 305, 108, and $414 \mu \mathrm{g} / 100 \mathrm{~g} \mathrm{FW}$, respectively. In an earlier study, Haynes et al. (2010) found no significant environmental effect on any of the carotenoids. Zeaxanthin, antheraxanthin, violaxanthin, and neoxanthin are on the LCY-b arm of the carotenoid biosynthetic pathway (Fig. 1). Thus, the significant difference between years for antheraxanthin, violaxanthin, and neoxanthin in this study seems to be caused by environmentally induced changes in one or more of the enzymes in this pathway. Zeaxanthin epoxidase and violaxanthin de-epoxidase interconvert zeaxanthin, antheraxanthin, and

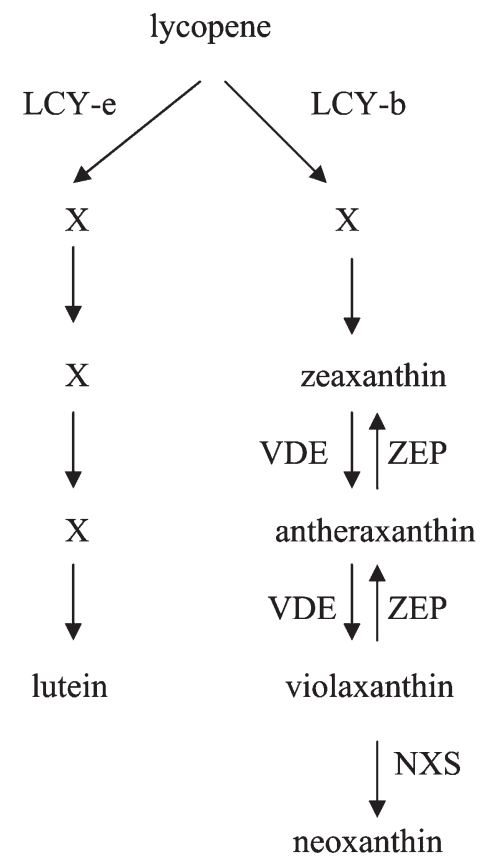

Fig. 1. Carotenoid biosynthetic pathway for carotenoids identified in potato. Intermediate carotenoids in the pathway, which have not been identified in potatoes, are shown by X. The pathway branches from lycopene. The lycopene epsilon-cyclase (LCY-e) branch gives rise to lutein. The lycopene beta-cyclase (LCY-b) branch gives rise to zeaxanthin, antheraxanthin, violaxanthin, and neoxanthin. Zeaxanthin epoxidase (ZEP) and violaxanthin de-epoxidase (VDE) interconvert zeaxanthin, antheraxanthin, and violaxanthin. Neoxanthin synthase (NXS) converts violaxanthin to neoxanthin (adapted from Diretto et al., 2006). violaxanthin, but the conversion of violaxanthin to neoxanthin by neoxanthin synthase appears to be unidirectional (Diretto et al., 2006). Although the pathways of carotenogenesis are known, regulation of gene expression for controlling these pathways is not well understood. Wolters et al. (2010) identified a recessive allele of zeaxanthin epoxidase, designated Zep allele 1, which when presents in the homozygous condition and in the presence of the beta-carotene hydroxylase Chy 2 allele 3 resulted in an orange-flesh color and higher levels of zeaxanthin. Romer et al. (2002) reported that downregulation of the gene for zeaxanthin epoxidase promoted zeaxanthin accumulation, consistent with restricted synthesis of downstream carotenoids. However, Morris et al. (2004) found that the relative expression levels of zeaxanthin epoxidase, violaxanthin de-epoxidase, and neoxanthin synthase in mature tubers were greater in germplasm with lower carotenoid content than germplasm with higher carotenoid content. How these lower levels of transcripts stimulate carotenogenesis is unknown. It is also possible that environmental differences influence the biosynthetic pathway before the synthesis of zeaxanthin. The most obvious environmental difference was the result of water stress in August. The crop had only approximately half the amount of rainfall in Aug. 2009 that it did in Aug. 2008 because the farm was not irrigated.

Although the effect of specific environmental factors in potatoes has not been reported, environmental effects on carotenoid content have been reported for other crop species. Water deficits in sorghum (Sorghum spp.) at all stages of development have been reported to affect carotenoid levels (de Oliveira Neto et al., 2009) and in olives (Olea europaea) water deficits reduced carotenoid concentrations in leaves (Ben Ahmed et al., 2009). Low temperatures increased the ratios of lutein, neoxanthin, and xanthophyll-cycle carotenoids and decreased the ratio of $\beta$-carotene to chlorophyll $a+b$ in leaves of corn (Zea mays) (Haldimann, 1998). Lefsrud et al. (2005) found that lutein and $\beta$-carotene content in kale increased linearly with increasing air temperatures but decreased linearly with increasing air temperatures for spinach. Lefsrud et al. (2006) also found that irradiance levels affected the accumulation of lutein and $\beta$-carotene in kale and spinach. In potatoes, 'Yukon Gold', a yellow-fleshed cultivar, has occasionally produced whitefleshed tubers in farmer fields. In such cases, the plants were from low-lying areas that had been waterlogged in the later half of the growing season (K.G. Haynes and D. Kelly, personal communications).

There were significant differences among clones for zeaxanthin, total LCY-b pathway carotenoids, lutein, and total carotenoid (Table 1). Average zeaxanthin in the clones ranged from 57 to $280 \mu \mathrm{g} / 100 \mathrm{~g} \mathrm{FW}$; 'Yukon Gold' averaged $103 \mu \mathrm{g}$ / 100 g FW. Two clones, BTD0220-61 and BTD0223-45, were significantly higher in zeaxanthin than 'Yukon Gold' (Fig. 2). Average total LCY-b pathway carotenoids in the clones ranged from 177 to $548 \mu \mathrm{g} / 100 \mathrm{~g} \mathrm{FW}$; 'Yukon Gold' averaged $262 \mu \mathrm{g}$ / $100 \mathrm{~g}$ FW. Three clones, two from family BTD0220 and one from BTD0223, were significantly higher in total LCY-b pathway carotenoids than 'Yukon Gold'. Average lutein in the clones ranged from 62 to $169 \mu \mathrm{g} / 100 \mathrm{~g} \mathrm{FW}$; 'Yukon Gold' averaged 81 $\mu \mathrm{g} / 100 \mathrm{~g} \mathrm{FW}$. Three clones, BTD0218-8, BTD0218-21, and BTD0218-54, were significantly higher in lutein than 'Yukon Gold' (Fig. 3). Average total carotenoid in the clones ranged from 117 to $705 \mu \mathrm{g} / 100 \mathrm{~g} \mathrm{FW}$; 'Yukon Gold' averaged $103 \mu \mathrm{g}$ / $100 \mathrm{~g} \mathrm{FW}$. Five clones, two from family BTD0218, two from BTD0220, and one from BTD0223, were significantly higher in 
Table 1. Estimates of the variance parameters from the GLMMIX procedure in SAS (Version 9.2; SAS Institute, Cary, NC), broad-sense heritability $(\mathrm{H})$, and the $95 \%$ confidence interval $(\mathrm{CI})$ about $\mathrm{H}$ for individual and total carotenoids from 42 4x-2x potato clones and ' $Y u k o n$ Gold' grown in Presque Isle, ME, in 2008 and 2009.

\begin{tabular}{|c|c|c|c|c|c|c|c|}
\hline Variance parameter & Zeaxanthin & Antheraxanthin & Violaxanthin & Neoxanthin & Total LCY-bz & Lutein & Total \\
\hline Clones & $5,068^{* *}$ & 113 & 183 & 314 & $12,233^{* *}$ & $1,057 * *$ & $21,288^{* *}$ \\
\hline Error & 1 & 1 & 1 & 1 & 1 & 1 & 1 \\
\hline Upper 95\% CI & 0.86 & 0.53 & 0.57 & 0.69 & 0.85 & 0.87 & 0.90 \\
\hline Lower $95 \%$ CI & 0.51 & -0.62 & -0.47 & -0.07 & 0.49 & 0.57 & 0.65 \\
\hline
\end{tabular}

${ }^{\mathrm{z}}$ Sum of zeaxanthin, antheraxanthin, violaxanthin, and neoxanthin; LCY-b = lycopene beta-cyclase.

*, ** Significant at $P=0.05$ or 0.01 , respectively.

$\mathrm{CI}=$ confidence interval.

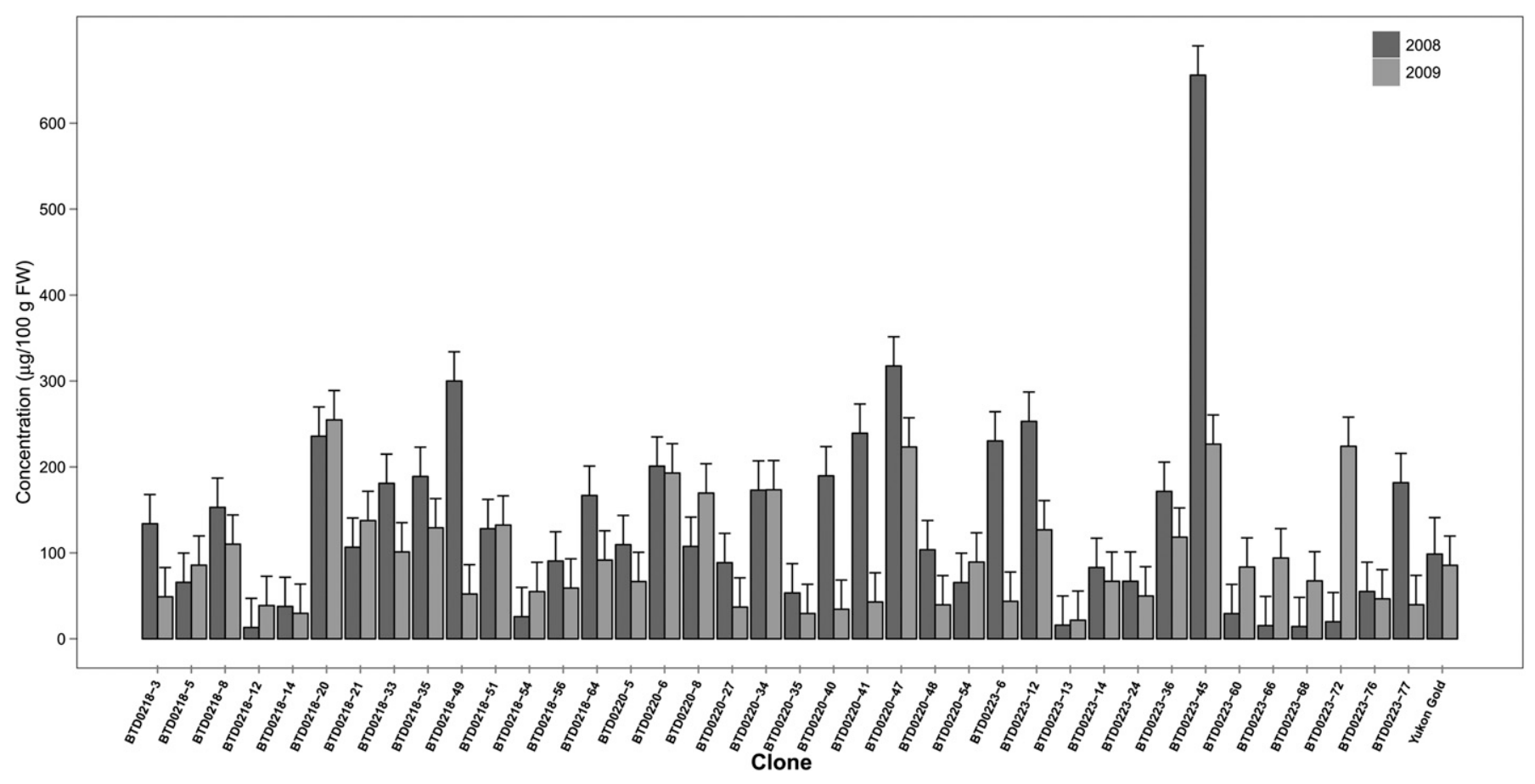

Fig. 2. Average zeaxanthin concentration for potato clones from three 4x-2x families and 'Yukon Gold' grown in Presque Isle, ME, in 2008 and 2009.

total carotenoid than 'Yukon Gold'. Numerous other researchers have found genetic variation for individual and/or total carotenoid content in potato germplasm (Andre et al., 2007; Brown et al., 1993, 2006; Haynes et al., 2010; Lu et al., 2001; Nesterenko and Sink, 2003; Reddivari et al., 2007; Tevini and Schonecker, 1986). Our results indicate that tetraploid clones with higher levels of individual and/or total carotenoids than 'Yukon Gold' can be bred.

The variation among clones could be further subdivided into variation among families and variation within families. There were no significant differences among the three families for any of the carotenoids or their totals nor was the year $\times$ among family variation for any of the carotenoids or their totals significant. Significant differences were found within families for zeaxanthin, total LCY-b pathway carotenoids, lutein, and the total. This is the first study we are aware of to examine the variation for carotenoid content among and within $4 \mathrm{x}-2 \mathrm{x}$ families. Brown et al. (1993) examined the variation for carotenoid content in diploid families for the orange-flesh trait in potato and postulated that the putative allele $\mathrm{Or}$ was responsible for the synthesis of large amounts of zeaxanthin and was dominant to the $y$ allele, which controls white pigmentation, and the $Y$ allele, which controls yellow pigmentation. However, Wolters et al. (2010) reported more recently that the orange-flesh trait was controlled by the dominant Chy 2 allele 3 in combination with the recessive Zep allele 1. Other studies have focused on examining the variation among clones and cultivars, but there was no inherent family structure in the germplasm in those studies. Thus, it appears that if at least one parent is yellow-fleshed, high- and low-carotenoid segregants will result. This also makes the development of high-carotenoid cultivars more difficult, because high-carotenoid clones can apparently result from any cross involving at least one yellow-fleshed clone.

Because the tetraploid parent of the $4 x-2 x$ derived progeny in our crosses was yellow-fleshed and because white-fleshed progeny were obtained from all crosses, the tetraploid parent must have been either simplex or duplex for Chy2. Because the diploid parent of family BTD0223 was white-fleshed, it 
must have been homozygous for chy2. There were 45 progeny in the BTD0223 family, segregating as 40 yellow-fleshed:five white-fleshed. Assuming chromosomal segregation, based on this segregation ratio, the tetraploid female parent must have been duplex: Chy2Chy2chy2chy2 (Table 2). The male parents, BD296-2 and BD317-4, were yellow-fleshed so they could have been homozygous or heterozygous for Chy2. In both the BTD0218 and BTD0220 families, white-fleshed progeny were observed (Table 2), so both diploid male parents (BD296-2 and BD317-4) had to have been heterozygous: Chy2chy2. Now a diploid clone that is heterozygous at a given locus can produce three kinds of $2 n$ gametes depending on the mechanism of $2 n$ gamete formation and $\beta$, where $0 \leq \beta \leq 1$. The only 2 n gametes that could produce white-fleshed tetraploid progeny are chy2chy2, which, if produced by a first division restitution mechanism, occur with a frequency of $\beta / 4$, and if produced by a second division restitution mechanism with a frequency of (1- $\beta / 2)$ (Mendiburu and Peloquin, 1979). Assuming chromo- somal segregation, the tetraploid parent is producing gametes chy 2 chy 2 with a frequency of $1 / 6$. Therefore, if $2 \mathrm{n}$ gametes were being produced by a first division restitution mechanism, the frequency of white-fleshed progeny would be $(1 / 6)(\beta / 4)$. Because $0 \leq \beta \leq 1$, the frequency of white-fleshed progeny would be somewhere between 0 and $1 / 24$. If $2 n$ gametes were being produced by a second division restitution mechanism, the frequency of white-fleshed progeny would be $(1 / 6)(1-\beta / 2)$ or between $1 / 12$ and $1 / 6$. Progeny of the BTD0218 family segregated 31 yellow-fleshed:five white-fleshed. The probability that $2 \mathrm{n}$ gametes were produced by a first division mechanism in this case was highly unlikely (Table 2 ) as chi squares were highly significant $\left(\chi^{2}>8.53, P<0.004\right)$. It is much more likely that the diploid parent (BD296-2) produced $2 \mathrm{n}$ gametes by a second division restitution mechanism because the segregation ratios from all possible values of $\beta$ fit the observed segregation ratios $\left(0.20 \leq \chi^{2} \leq 1.45,0.23 \leq\right.$ $P \leq 0.65)$. Progeny of the BTD0220 family segregated 20

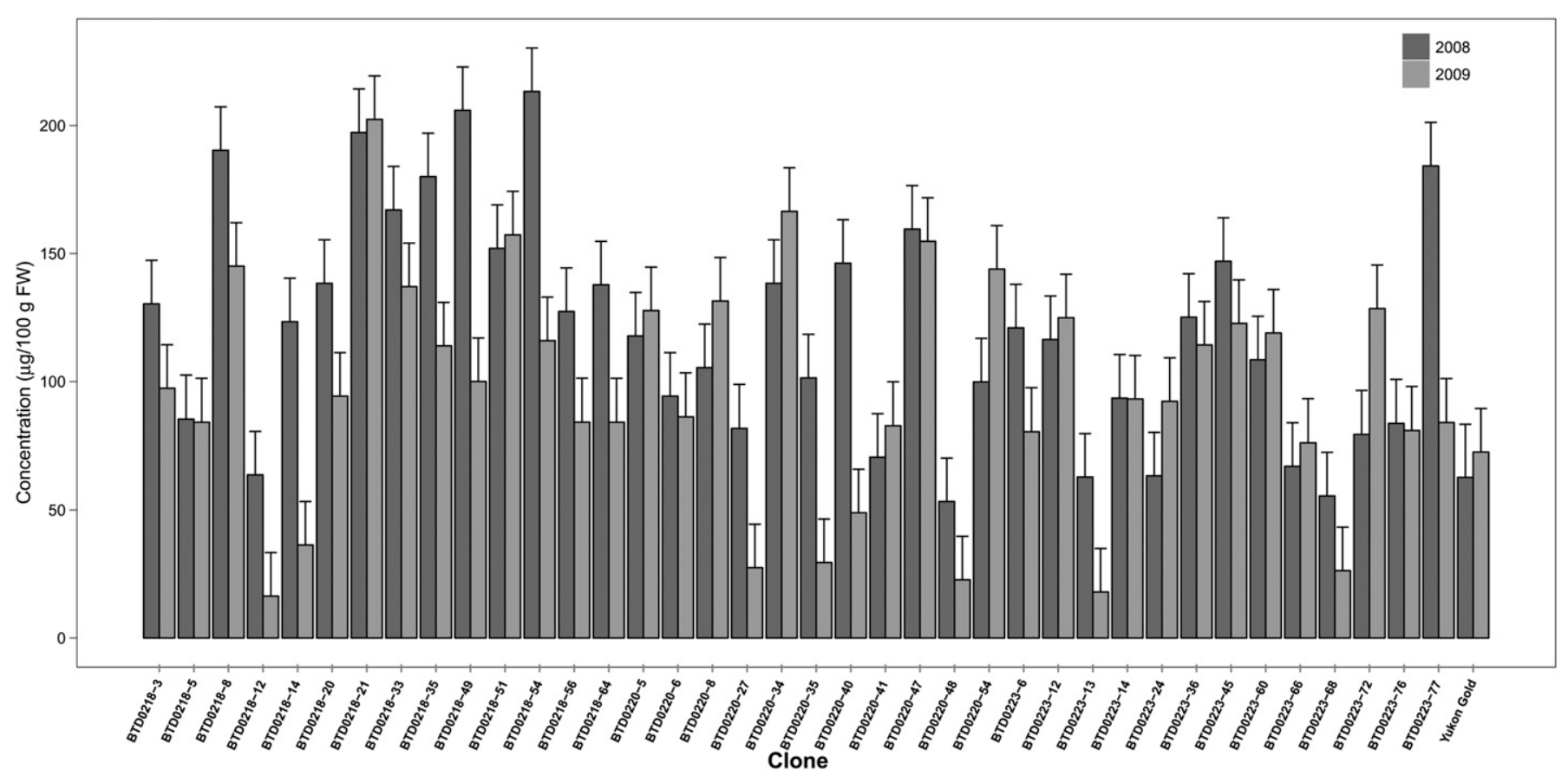

Fig. 3. Average lutein concentration for potato clones from three 4x-2x families and 'Yukon Gold' grown in Presque Isle, ME, in 2008 and 2009.

Table 2. Segregation ratios of yellow-fleshed (yel):white-fleshed (wh) progeny for three 4x-2x potato families evaluated for tuber flesh color, results of the chi-square test of goodness of fit for possible parental genotypes [for crosses involving two yellow-fleshed parents, assuming $2 \mathrm{n}$ gametes in the diploid parent were produced by a first division restitution mechanism (FDR) or second division restitution mechanism (SDR)], based on the putative genotype at the beta-carotene hydroxylase locus for each of the parents. ${ }^{\mathrm{z}}$

\begin{tabular}{lccccc}
\hline & & & \multicolumn{2}{c}{ Yel:wh progeny } \\
\cline { 4 - 7 } Family & Male parent & Phenotype & Possible genotypes & Observed & Expected \\
\hline BTD0223 & BD322-1 & yel $\times$ wh & Chy2Chy2chy2chy2 $\times$ chy2chy2 & $40: 5$ & $37.5: 7.5$ \\
& & & Chy2chy2chy2chy2 $\times$ chy2chy2 & $40: 5$ & $22.5: 22.5$
\end{tabular}

\begin{tabular}{|c|c|c|c|c|c|c|}
\hline \multirow[b]{2}{*}{ Family } & \multirow[b]{2}{*}{ Male parent } & \multirow[b]{2}{*}{ Phenotype } & \multirow[b]{2}{*}{ Possible genotypes } & \multicolumn{2}{|c|}{ Yel:wh progeny } & \multirow[b]{2}{*}{$\chi^{2}(\mathrm{SDR})$} \\
\hline & & & & Observed & $\chi^{2}(\mathrm{FDR})$ & \\
\hline BTD0220 & BD317-4 & yel $\times$ yel & Chy 2 Chy 2 chy 2 chy $2 \times$ Chy 2 chy 2 & $20: 6$ & $>23.37$ & $0.77-7.38$ \\
\hline
\end{tabular}

${ }^{\mathrm{z}}$ The yellow-fleshed female parent, B1425-9, was the same in all three families.

$\mathrm{NS}=$ non-significant. 
yellow-fleshed:six white-fleshed. The probability that 2 n gametes were produced by a first division restitution mechanism in this case is even more unlikely than in the BTD0218 family $\left(\chi^{2}>23.37, P<0.0001\right)$ (Table 2). Once again, it is much more likely that the diploid parent (BD317-4) produced $2 \mathrm{n}$ gametes by a second division restitution mechanism $\left(0.77 \leq \chi^{2} \leq 7.38\right.$, $0.0065 \leq P \leq 0.38)$ with a frequency of single exchange tetrads closer to $1 / 6\left(\chi^{2}=0.77, P=0.38\right)$ than to $1 / 12\left(\chi^{2}=7.38, P=\right.$ $0.065)$. Although $2 n$ pollen is formed predominantly by a first division restitution mechanism (Watanabe and Peloquin, 1989), the production of $2 n$ pollen by second division restitution mechanisms has also been reported (Mok et al., 1976; Watanabe and Peloquin, 1989).

Several researchers have estimated the gene-centromere linkage for $Y$, a yellow-flesh marker, using half-tetrad analysis (Douches and Quiros, 1987; Mok et al., 1976; Stelly and Peloquin, 1986). These results have been consistent, ranging from 12 to $16 \mathrm{cM}$, or a recombination rate of $12 \%$ to $16 \%$, which would result from a frequency of single exchange tetrads of $24 \%$ to $32 \%$. Using these estimates of $\beta$ based on previously published gene-centromere mapping results, if $2 n$ pollen was produced by a first division restitution mechanism (FDR) mechanism in either BD296-2 or BD317-4, the frequency of white-fleshed progeny in the BTD0218 or BTD0220 families would range between 0.0100 and 0.0133 or less than one whitefleshed progeny. However, if $2 n$ pollen were produced by a second division restitution mechanism (SDR) mechanism in either of these diploid yellow-fleshed parents, the frequency of white-fleshed progeny in the BTD0218 or BTD0220 families would range between 0.140 and 0.147 , or $\approx 5$ for BTD0218, which is what was observed, and $\approx 4$ for BTD0220, which is close to what was observed.

Tubers for this study were held in storage at $4{ }^{\circ} \mathrm{C}$ and then warmed up 1 to $3 \mathrm{~d}$ before carotenoids were extracted. It took nearly 4 months to do all the extractions as a result of the large number of samples. Reports on the fate of carotenoids in storage have been inconsistent. Haynes et al. (2009) found slight increases in total carotenoids, violaxanthin, neoxanthin, antheraxanthin, and lutein in the two tetraploid cultivars they screened monthly during storage at $10{ }^{\circ} \mathrm{C}$ over 6 months. However, in examining tubers stored at $4{ }^{\circ} \mathrm{C}$ for 9 months from two tetraploid cultivars and one diploid selection, Morris et al. (2004) found that the total carotenoid content in one cultivar increased slightly, dropped greatly in the second cultivar, and was unchanged in the diploid selection. Griffiths et al. (2007) reported significant decreases in total carotenoid content in tubers from diploid selections stored for 12 weeks at $10^{\circ} \mathrm{C}$ and even greater decreases when stored for 12 weeks at $4{ }^{\circ} \mathrm{C}$. To minimize any possible confounding effect with storage in our study, carotenoids were extracted from tubers from the first replication within the first 6 weeks of storage and from the second replication after 6 weeks of storage.

Brown (2008) stated that the North American potato gene pool would need an infusion of genetic variation from South American cultivars to boost total carotenoids. Although not involved in imparting yellow-flesh color, Wolters et al. (2010) present evidence that several Chy 2 alleles are unique to diploid potato germplasm. In addition, although not involved in imparting orange-flesh color, they suggested that several minor Zep alleles present in cultivars released after 1960 probably also originated from diploid potato germplasm. The diploid species used as parents in this study were from the South American short-day adapted species S. phureja and S. stenotomum, which had undergone extensive selection for adaptation to the longday conditions that characterize most potato-growing regions in North America (Haynes, 1972, 2008). Five of the $414 x-2 x$ clones from these diploid parents were significantly higher in total carotenoids than 'Yukon Gold', which tends to support Brown's assertion. Interestingly, there was at least one highcarotenoid segregant from each of the three families, even from the family with the white-cream-fleshed diploid parent.

Significant year $\times$ clone interactions were found for all carotenoids (Table 1). Some of the carotenoids in some clones were fairly consistent between the 2 years, whereas the concentration of many of the carotenoids was much higher in 2008 than in 2009 for many clones. For a few clones, the concentration of some of the carotenoids was lower in 2008 than in 2009. These results agree with others (Haynes et al., 2010; Reddivari et al., 2007) who found significant genotype $\times$ environment interactions on carotenoid concentrations. In general, these significant interactions accounted for a small amount of the overall variation, although in this particular study, this is not the case for antheraxanthin and violaxanthin and, to a lesser extent, neoxanthin.

Broad-sense heritabilities, which estimate the total amount of genetic variation as a proportion of the total variation, were high for zeaxanthin (0.73), total LCY-b carotenoids $(0.73)$, lutein $(0.77)$, and total carotenoids $(0.81)$; moderate for neoxanthin (0.42); and low for antheraxanthin (0.13) and violaxanthin $(0.21)$ (Table 1). Haynes et al. (2010) likewise obtained high estimates of heritabilities for total carotenoid, zeaxanthin, total LCY-b carotenoids, and lutein in predominantly $S$. tuberosum germplasm. Once again, the anomaly with past results resides in some of the carotenoids in the LCY-b pathway: namely, violaxanthin, antheraxanthin, and neoxanthin, for which genotype $\times$ environment interactions are much more important in this study than in other studies (Haynes et al., 2010; Reddivari et al., 2007).

Potatoes are an ideal crop for nutritional enhancement. Potatoes are already an excellent food source. Potato protein is high quality, composed of all the essential amino acids necessary in the human diet. A small potato $(\approx 6.4 \mathrm{~cm}$ diameter; 148-g Nutrition Labeling and Education Act serving) provides $7 \%$ of kcal for a $2000-\mathrm{kcal}$ diet and delivers more than $10 \%$ daily value (DV) of folate, manganese, magnesium, and phosphorus and more than $20 \%$ DV of potassium, vitamin C, and vitamin B6. Potatoes are also a good source of fiber. On a per-acre basis, potatoes provide more dry matter and protein per unit growing area than do cereal crops (Bamberg and del Rio, 2005). Because of their high yield potential and nutritional value, potato production and consumption have been increasing in developing countries for decades (Centro Internactional de le Papa, 2009). In the decade from 1990-1992 to 2000-2002, the average daily consumption of potatoes increased in all regions of the world. Over this time period, average consumption increased by $47 \%$ in Africa and Asia, by $41 \%$ in Central America, by $37 \%$ in Polynesia, by $29 \%$ in the Middle East, by $27 \%$ in Central Asia, by $10 \%$ in South America, by $6 \%$ in North America (U.S. and Canada) and Oceania, and by 2\% in Europe (Food and Agriculture Organization of the United Nations, 2010).

Of the carotenoids present in potatoes, lutein and zeaxanthin are currently of most interest because of their known health benefits. These two carotenoids are present in dark green leafy vegetables, but zeaxanthin is less abundant (Sommerburg et al., 
1998). With the elucidation of the genes involved in the orangeflesh phenotype in potatoes, breeding strategies can now be effectively deployed to develop orange-flesh and hence high zeaxanthin potatoes.

Even modest increases in carotenoid concentrations in potatoes could have a substantial positive impact on human health worldwide. The literature has shown that the carotenoid content of potatoes can be enhanced either through breeding (Brown et al., 1993; this study) or genetic engineering through overexpressing a gene encoding a rate-limiting step (Ducreux et al., 2005) or silencing a biosynthetic step downstream of the desired carotenoid (Romer et al., 2002). Increasing the carotenoid content of potatoes would make an already nutritious food even more nutritious.

\section{Literature Cited}

Andre, C.M., M. Oufir, C. Guignard, L. Hoffmann, J.-F. Hausman, D. Evers, and Y. Larondelle. 2007. Antioxidant profiling of native Andean potato tubers (Solanum tuberosum L.) reveals cultivars with high levels of $\beta$-carotene, $\alpha$-tocopherol, chlorogenic acid, and petanin. J. Agr. Food Chem. 55:10839-10849.

Bamberg, J.B. and A. del Rio. 2005. Conservation of genetic resources, p. 1-38. In: Razdan, M.K. and A.K. Mattoo (eds.). Genetic improvement of Solanaceous crops. Vol. 1: Potato. Science Publishers, Enfield, NH.

Ben Ahmed, C., B. Ben Rouina, S. Sensoy, M. Boukhris, and F. Ben Abdallah. 2009. Changes in gas exchange, proline accumulation and antioxidative enzyme activities in three olive cultivars under contrasting water availability regimes. Environ. Exp. Bot. 67:345352.

Brown, C.R. 2008. Breeding for phytonutrient enhancement of potato. Amer. J. Potato Res. 85:298-307.

Brown, C.R., C.G. Edwards, C.-P. Yang, and B.B. Dean. 1993. Orange flesh trait in potato: Inheritance and carotenoid content. J. Amer. Soc. Hort. Sci. 118:145-150.

Brown, C.R., T.S. Kim, Z. Ganga, K. Haynes, D. De Jong, M. Jahn, I. Paran, and W. De Jong. 2006. Segregation of total carotenoid in high level potato germplasm and its relationship to beta-carotene hydroxylase polymorphism. Amer. J. Potato Res. 83:365-372.

Centro Internactional de la Papa. 2009. Potato/CIP potato facts: Potato: Growth in production accelerates. 17 Feb. 2011. <http://www.cipotato. org/potato/facts/growth.asp>.

de Oliveira Neto, C.F., A.K. da Silva Lobato, M.C. Goncalves-Vidigal, R.C.L. da Costa, B.G. dos Santos Filho, G.A.R. Alves, W.J. de Mello e Silva Maia, F.J.R. Cruz, H.K.B. Neves, and M.J. dos Santos Lopes. 2009. Carbon compounds and chlorophyll contents in sorghum submitted to water deficit during three growth stages. J. Food Agric. Environ. 7:588-593.

Diretto, G., R. Tavazza, R. Welsch, D. Pizzichini, F. Mourgues, V. Papacchioli, P. Beyer, and G. Giuliano. 2006. Metabolic engineering of potato tuber carotenoids through tuber-specific silencing of lycopene epsilon cyclase. BMC Plant Biol. 6:13.

Douches, D.S. and C.F. Quiros. 1987. Use of $4 \mathrm{x}-2 \mathrm{x}$ crosses to determine gene-centromere map distances of isozyme loci in Solanum species. Genome 29:519-527.

Ducreux, L.J.M., W.L. Morris, P.E. Hedley, T. Shepherd, H.V. Davies, S. Milliam, and M.A. Taylor. 2005. Metabolic engineering of high carotenoid potato tubers containing enhanced levels of $\beta$-carotene and lutein. J. Expt. Bot. 56:81-89.

Food and Agriculture Organization of the United Nations. 2010. Food and agricultural commodities production. 17 Feb. 2011. <http:// faostat.fao.org/site/339/default.aspx>.

Fruwirth, C. 1912. Zur Zuchtung der Kartoffel. Deutsche Landwirtschaft Presse 39:551-552, 565-567.

Griffiths, D.W., M. Finlay, B. Dale, W.L. Morris, and G. Ramsey. 2007. Effects of season and postharvest storage on the carotenoid content of Solanum phureja potato tubers. J. Agr. Food Chem. 55: 379-385.

Haldimann, P. 1998. Low temperature-induced changes to pigment composition and photosynthesis in Zea mays genotypes differing in chilling sensitivity. Plant Cell Environ. 21:200-208.

Haynes, F.L. 1972. The use of cultivated diploid Solanum species in potato breeding, p. 100-110. In: French, E.R. (ed.). Prospects for the potato in the developing world. Centro Internatiocional de la Papa, Lima, Peru.

Haynes, K.G. 1990. Covariances between diploid parent and tetraploid offspring in tetraploid $\times$ diploid crosses of Solanum tuberosum L. J. Hered. 81:208-210.

Haynes, K.G. 2008. Heritability of chip color and specific gravity in a long-day adapted Solanum phureja $\times S$. stenotomum population. Amer. J. Potato Res. 85:361-366.

Haynes, K.G., B.A. Clevidence, D. Rao, B.T. Vinyard, and J.M. White. 2010. Genotype $\times$ environment interactions for potato tuber carotenoid content. J. Amer. Soc. Hort. Sci. 135:250-258.

Haynes, K.G., B.A. Clevidence, D.D. Rao, and B.T. Vinyard. 2009. Stability of potato tuber carotenoid content in storage. Amer. J. Potato Res. 86:146.

Haynes, K.G., F.L. Haynes, and W.R. Henderson. 1989. Heritability of specific gravity of diploid potato under high temperature growing conditions. Crop Sci. 29:622-625.

Johnson, E.J., K. McDonald, S.M. Caldarella, H. Chung, A.M. Troen, and D.M. Snodderly. 2008. Cognitive findings of an exploratory trial of docosahexaenoic acid and lutein supplementation in older women. Nutr. Neurosci. 11:75-83.

Lefsrud, M.G., D.A. Kopsell, D.E. Kopsell, and J. Curran-Celentano. 2005. Air temperature affects biomass and carotenoid pigment accumulation in kale and spinach grown in a controlled environment. HortScience 40:2026-2030.

Lefsrud, M.G., D.A. Kopsell, D.E. Kopsell, and J. Curran-Celentano. 2006. Irradiance levels affect growth parameters and carotenoid pigments in kale and spinach grown in a controlled environment. Physiol. Plant. 127:624-631.

Lu, W., K. Haynes, E. Wiley, and B. Clevidence. 2001. Carotenoid content and color in diploid potatoes. J. Amer. Soc. Hort. Sci. 126: $722-726$.

Mares-Perlman, J.A., A.E. Millen, T.L. Ficek, and S.E. Hankinson. 2002. The body of evidence to support a protective role for lutein and zeaxanthin in delaying chronic disease. Overview. J. Nutr. 132: 518S-524S.

Mendiburu, A.O. and S.J. Peloquin. 1979. Gene-centromere mapping by $4 x-2 x$ matings in potato. Theor. Appl. Genet. 54:177-180.

Mok, D.W.S. and S.J. Peloquin. 1975. Breeding value of $2 \mathrm{n}$ pollen (diplandroids) in tetraploid $\times$ diploid crosses in potatoes. Theor. Appl. Genet. 46:307-314.

Mok, D.W.S., S.J. Peloquin, and A.O. Mendiburu. 1976. Genetic evidence for mode of $2 \mathrm{n}$ pollen formation and S-locus mapping in potatoes. Potato Res. 19:157-164.

Morris, M.C., D.A. Evans, C.C. Tangney, J.L. Bienias, and R.S. Wilson. 2006. Associations of vegetable and fruit consumption with age-related cognitive change. Neurology 67:1370-1376.

Morris, W.L., L. Ducreux, D.W. Griffiths, D. Stewart, H.V. Davies, and M.A. Taylor. 2004. Carotenogenesis during tuber development and storage in potato. J. Expt. Bot. 55:975-982.

Nesterenko, S. and K.C. Sink. 2003. Carotenoid profiles of potato breeding lines and selected cultivars. HortScience 38:1173-1177.

Nyquist, W.E. 1991. Estimation of heritability and prediction of selection response in plant populations. Crit. Rev. Plant Sci. 10: 235-322.

Reddivari, L., A.L. Hale, and J.C. Miller, Jr. 2007. Genotype, location, and year influence antioxidant activity, carotenoid content, phenolic content, and composition of specialty potatoes. J. Agr. Food Chem. 55:8073-8079.

Romer, S., J. Lubeck, F. Kauder, S. Steiger, C. Adomat, and G. Sandmann. 2002. Genetic engineering of a zeaxanthin-rich potato by 
antisense inactivation and co-suppression of carotenoid epoxidation. Metab. Eng. 4:263-272.

Sommerburg, O., J.E.E. Keunen, A.C. Bird, and F.J.G.M. van Kuijk. 1998. Fruits and vegetables that are sources for lutein and zeaxanthin: The macular pigment in human eyes. Brit. J. Opththalmology 82:907-910.

Stelly, D.M. and S.J. Peloquin. 1986. Diploid female gametophyte formation in 24-chromosome potatoes: Genetic evidence for the prevalence of the second division restitution mode. Can. J. Genet. Cytol. 28:101-108.
Tevini, M. and G. Schonecker. 1986. Occurrence, properties, and characterization of potato carotenoids. Potato Res. 29:265.

Watanabe, K. and S.J. Peloquin. 1989. Occurrence of $2 \mathrm{n}$ pollen and ps gene frequencies in cultivated groups and their related wild species in tuber-bearing Solanums. Theor. Appl. Genet. 78:329336.

Wolters, A.M., J.G.A.M.L. Uitdewilligen, B.A. Kloosterman, R.C.B. Huttten, R.G.F. Visser, and H.J. van Eck. 2010. Identification of alleles of carotenoid pathway genes important for zeaxanthin accumulation in potato tubers. Plant Mol. Biol. 73:659-671. 